\title{
Study of Diamond Film Interface Structure and Contacting Area
}

\author{
Paisan Setasuwon*, Thanapak Metanawin \\ ${ }^{a}$ National Metal and Materials Technology Center, Thailand \\ ${ }^{\mathrm{b}}$ School of Energy, Environment and Materials, King Mongkut's \\ University of Technology Thonburi
}

Received: September 22, 2008; Revised: December 26, 2008

\begin{abstract}
High purity diamond film has been grown by refined Combustion Flame method with high oxygen proportion. Snapshots of time series of the diamond film forming were taken and a model was derived. By observing the period of seeding to coalescing of diamond crystals to form film, it is realized that the contacting area is small and the calculated value was less than $15 \%$. It is also found that the base layer of the film was porous as a result of non-uniform crystal growth. To enhance adhesion of the film, the contacting area between the film and the substrate must be increased, and the porous base layer must be thin and dense as much as possible. To achieve that, very high and uniform nucleation is the key. Under this view, the nanocrystalline diamond film on smooth substrate is preferred than rough surface to have strong adhesion.
\end{abstract}

Keywords: diamond film, combustion flame, interfacial structure, contacting area

\section{Introduction}

Diamond possesses a combination of extreme properties, such as highest hardness, very low friction coefficient and highest thermal conductivity. Chemical vapor deposition (CVD) enables the manufacturing of diamond in the form of film at low cost. As one of CVD, Combustion Flame methods deposit diamond at high rates (typically $100-1,000 \mu \mathrm{m} / \mathrm{h}$ ), but often only over very small localized areas and with poor process control resulting in poor quality films. However, the quality of the films by Combustion Flame methods could be improved and the acceptable quality diamond film could be produced for applications such as an abrasive and coating on cutting tool inserts, drill bits, borer, milling cutter, etc.

The diamond film then is an ideal coating for tools with cemented carbide as substrate materials. The biggest concern is the poor adhesion of the diamond film from the detrimental effects of the binders (e.g. Co) on diamond nucleation. With reduction of surface cobalt, adhesion of diamond film with WC substrate could be enhanced remarkably ${ }^{2}$. Mechanical or chemical pretreatments, interlayers or combinations of these methods are applied to improve nucleation and adhesion strength ${ }^{3-7}$. All of these techniques are related to the final film structure which determined the adhesion strength. However, no detailed investigation of the structure of the film interface was performed to increase understanding the film adhesion strength numerically.

The aim of this study was to employ improved high-oxygen combustion flame to produce high quality diamond film on the surface of WC-Co, which was pretreated for high nucleation, to investigate the formation of the film step by step and to identify any aspects of the film that could be improved to increase the adhesion of the diamond film.

\section{Experimental}

The refined Combustion Flame CVD was employed for fabrication of continuous diamond film with high purity. Figure 1 shows a schematic illustration of the diamond coating apparatus used in this study. Oxygen $\left(\mathrm{O}_{2}\right)$ with $99.8 \%$ purity and acetylene $\left(\mathrm{C}_{2} \mathrm{H}_{2}\right)$ with $99.5 \%$ purity were used. Gas flow rate was measured with flowmeters (Gilmont instruments GF6541-1215 and GF-6541-1225). The welding torch was COMET with a No. 8 tip.

The substrates were WC/Co (4 wt. (\%) Co) with the dimension of $9 \times 9 \times 5 \mathrm{~mm}$. with slight tapering. The substrate was inserted in the slot on the copper box with water-cooling. The temperature was monitored at the side of the specimen, using thermocouple type $\mathrm{K}$ with the temperature reader (Carlo Gavazzi Instruments SPA LDI 35). Substrate in this study was pretreated by immersion in etchant for 30 seconds at room temperature. The etchant composition was listed in ASTM E407 ${ }^{\circ}$. Then, it was followed by scratching treatment with $1 \mu \mathrm{m}$ diamond powder on the polishing cloth for 1 minute. After scratching, the substrate was cleaned with detergent, distilled water and dried. For examination of the surface morphology, the scanning electron microscope JSM-6301F was employed. The identification of the presence of diamond and other forms of carbon was performed using Renishaw Ramanscope System 2000.

The experiments were performed in air at normal atmospheric pressure. Acetylene and oxygen flow rates were 1.21 and $1.37 \mathrm{~L} \cdot \mathrm{min}^{-1}$, respectively. The ratio of oxygen per acetylene $\left(\mathrm{O}_{2} / \mathrm{C}_{2} \mathrm{H}_{2}\right)$ was 1.13 . The substrate was located at $1 \mathrm{~mm}$. away from the tip of the inner flame. The temperature of the substrate was maintained at $700{ }^{\circ} \mathrm{C}$. The time for growing diamond film was varied from 0 to 10 minutes. A series of snapshots of various deposition times from nucleation to film forming was taken. Top-viewed 2-dimensional SEM micrographs were transformed to schematic drawing model of film forming. The number of seeds or nuclei was plotted against time. Contacting area percentage was calculated.

\section{Results and Discussion}

Theoretically, the acetylene/oxygen flow ratio for producing diamond film is equal to one. However, in practice this ratio as determined by the read-out of the flowmeters, is different from unity 


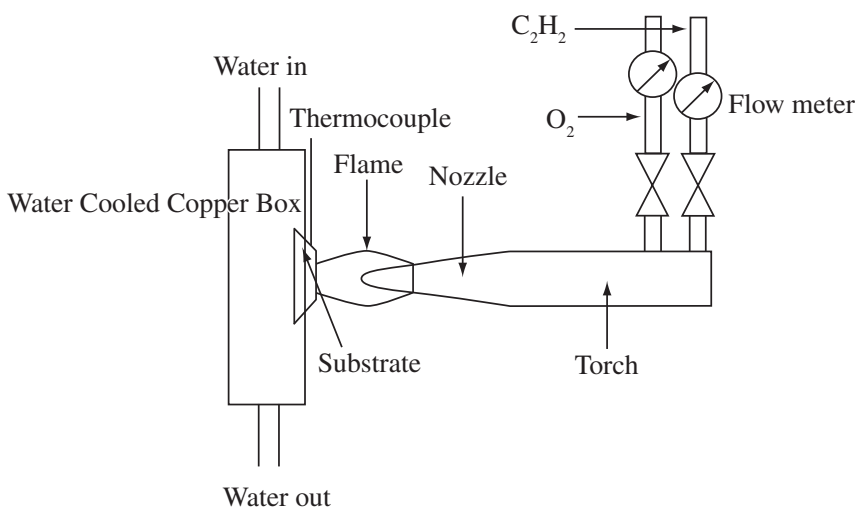

Figure 1. Schematic illustration of the diamond coating apparatus.

due to the burner geometry dependent kinetics of the combustion process and the cylinder pressure dependent take-up of acetone in the acetylene flow ${ }^{9}$. Higher oxygen has been incorporated to enhance the etching of non-diamond phases ${ }^{10}$. Refined combustion CVD with high oxygen proportion was employed to produce high quality diamond film in this study.

Micrographs of the growth of diamond at various times are shown in Figure 2. Figure 2a shows the microstructure after 3 minutes, it is similar to that of the original as-treated surface. At 3.5 minutes, diamond nuclei were noticeable- they grew larger and increased in number during the $4^{\text {th }}$ and $5^{\text {th }}$ minute (Figures $2 \mathrm{c}$ and $\mathrm{d}$ ). The diamond crystals started to join into a porous film (Figure 2e) and a dense film after 10 minutes (Figure 2f). The diamond crystals in the film are almost oriented with $\{111\}$ facets. Raman spectrum showed that the film was composed of pure diamond with no other forms of carbon (Figure 3).

The crystal density was plotted in Figure 4. The nucleation density or the diamond crystal density before forming film was $5.5 \times 10^{7}$ crystals. $\mathrm{cm}^{-2}$ after 3.5 minutes and increased to the highest value of about $1.2 \times 10^{8}$ crystals.cm ${ }^{-2}$ after 4 minutes. As time increased, the diamond crystal density decreased rapidly to the approximate value of $6.5 \times 10^{7}$ crystals. $\mathrm{cm}^{-2}$. It has shown that the crystal density of the film is less than the observed maximum. The diamond crystal density does not depend only on the nucleation density but also the competitive growth among diamond crystals. The competitive growth results in nearly half the maximum value.

Figure 5 shows the cross-sectional view of the fracture of the film that peeled off after prolonged exposure to the flame (20 minutes). The crystal morphology in the thick film was columnar and dense. For common Combustion Flame method, the growth of diamond was found to be dendritic ${ }^{11}$ and the film was porous, but this refined Combustion Flame CVD and surface pretreatment gave the columnar structure as achieved by another improved combustion method ${ }^{12}$. Although this refined combustion method could produce the diamond film with improved characteristics, the coating area was limited to just $5 \mathrm{~mm}$. in diameter, and the growth rate was measured to be just $10 \mu \mathrm{m} / \mathrm{h}$ as a trade-off for high quality diamond. The growth rate was highest at the center and lowest at the perimeter of the coating area. These limitations could be improved further by the modification of the instruments to increase the coating area and uniformity throughout the coating area.

\section{Growth Model of Diamond Film with High Nucleation Density}

Derived from this study, a specific growth model of diamond film was constructed (Figure 6). The cross-sectional views were reasonably induced from the top-viewed SEM micrographs in Figure 2. The model shows that a number of diamond nuclei originate on the surface at the early exposure to the flame, especially at grooves (Figure 6a). As time increases, the number of nuclei increases and some grow larger. At the next stage, some crystals touch the neighboring ones. Small islands of crystals are formed and join into a porous layer (Figure 6e). Competitive growth becomes crucial when the diamond crystals touch the others and some crystals grow larger at the expense of the others. This results in decrease of crystals density as found experimentally (Figure 4). When joining of islands of diamond crystals completes, a continuous film is produced (Figure $6 \mathrm{f}$ ). The growth of the diamond crystals in the film is then in the direction of the supply of carbon source (or to the flame), resulting in dense columnar structure (Figure 6g).

From this model, the footprint of the film is not a replica of the substrate surface and the base layer is also porous (Figure $6 \mathrm{~h}$ ). These important aspects are not shown in an earlier model ${ }^{11}$ which does not take surface roughness and competitive growth into consideration. There are reports on the porous intermediate layer of $\mathrm{TiC}$ on titanium substrate $^{13}$, and some porous structure in the diamond film ${ }^{1}$.

As the adhesion strength is directly related to the contacting area between the film and the substrate, neither the bottom area of the film nor the area of the substrate surface under the film could be counted as contacting area. The best estimation of contacting area should rather be implied from the crystal density of the first continuous film, which is $6.5 \times 10^{7}$ crystals.cm ${ }^{-2}$ (Figure 4). The early higher nucleation density (Figure 4 ) could not be employed since some crystals do not grow fast enough to participate in the forming of the film before the film covers the surface and the further growth of crystals underneath is prohibited.

The contacting area of the film is the product of crystal density and the contacting area of each crystal. Since each diamond crystal is bound, the substrate through its apex only $y^{6,14}$. it is assumed that the crystal size at the first noticeable stage, $0.3-0.5 \mu \mathrm{m}$. from Figure $2 \mathrm{~b}$, is the diameter of contacting area of each crystal. With the crystal density of $6.5 \times 10^{7}$ crystals. $\mathrm{cm}^{-2}$, the contacting area of $1 \mathrm{~cm}^{2}$ film is just $0.05-0.14 \mathrm{~cm}^{2}$, or as low as $5-14 \%$ of the substrate area, and will be less if the surface roughness is considered. The adhesion strength could be much further improved by increasing contacting area via increased nucleation density.

There are emerging techniques to increase the nucleation density substantially, i.e., negative bias ${ }^{15-20}$, seeding with nano-particles ${ }^{21}$, nano-layer of diamond-like carbon interlayer ${ }^{22}$ and very low pressure $^{14}$. These techniques could produce very high nucleation density up to $10^{11}$ crystals. $\mathrm{cm}^{-2}$. By varying pressure of the synthesis chamber, nucleation density range of $5 \times 10^{10}$ crystals. $\mathrm{cm}^{-2}$ could be achieved ${ }^{14}$ with the approximated nucleus diameter of $0.04 \mu \mathrm{m}$. The total contacting area is calculated to be $62.9 \%$. To increase the contacting area to $100 \%$, the nucleation density must be increased to $8 \times 10^{10}$ crystals.cm ${ }^{-2}$. At $100 \%$ contacting area, continuous film is formed with the nanocrystals of estimated nucleus diameter of approximate $40 \mathrm{~nm}$.

Another important aspect of the film structure limiting adhesion strength is the porous interface layer. The existence of porous interface layer is in disagreement with the idea of the film failure under the stress from the thermal expansion mismatch between diamond film and substrate ${ }^{23}$. High porosity layer is a good stress relaxation buffer for the thermal expansion mismatch. The peeling-off failure 

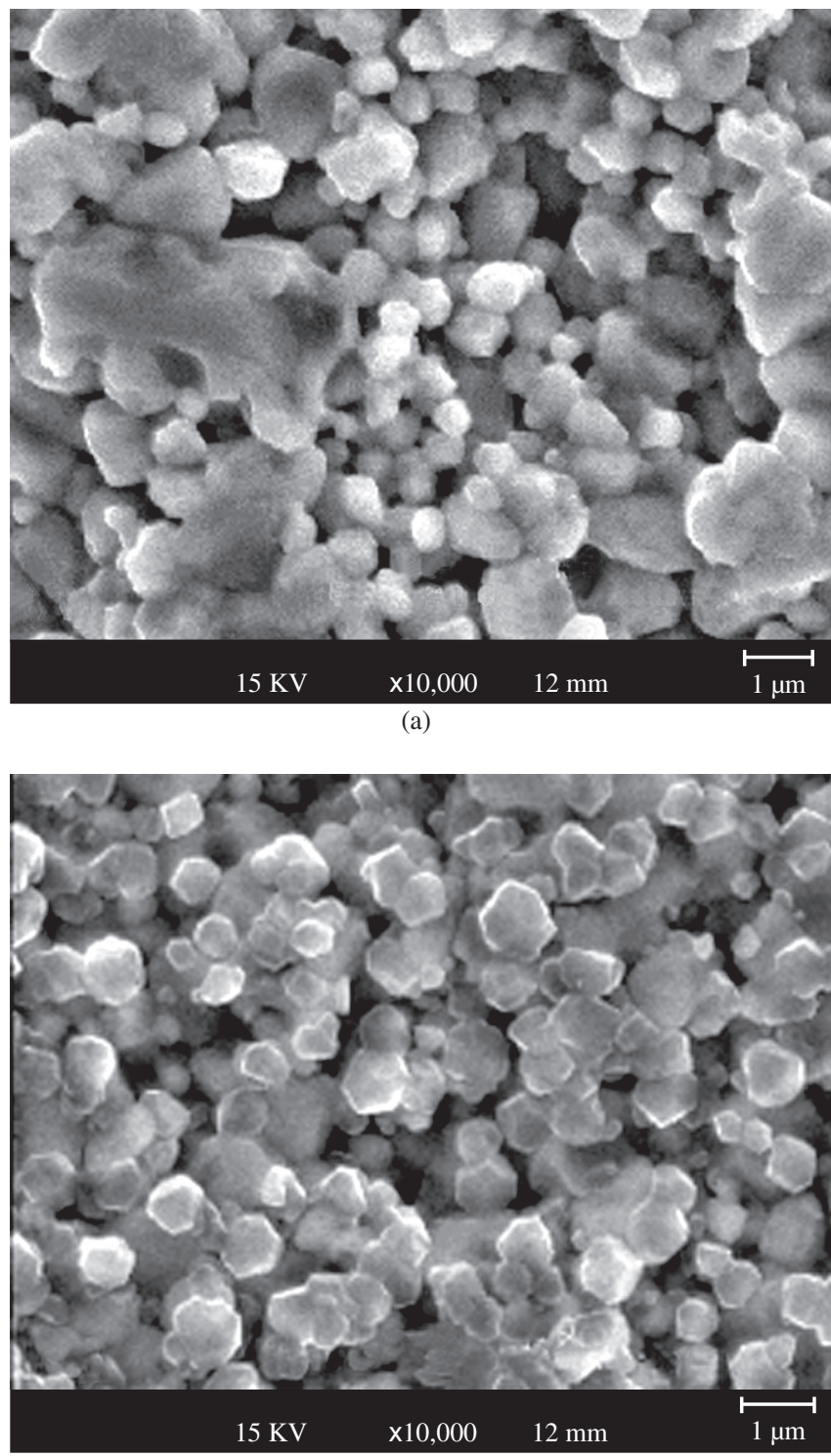

(c)

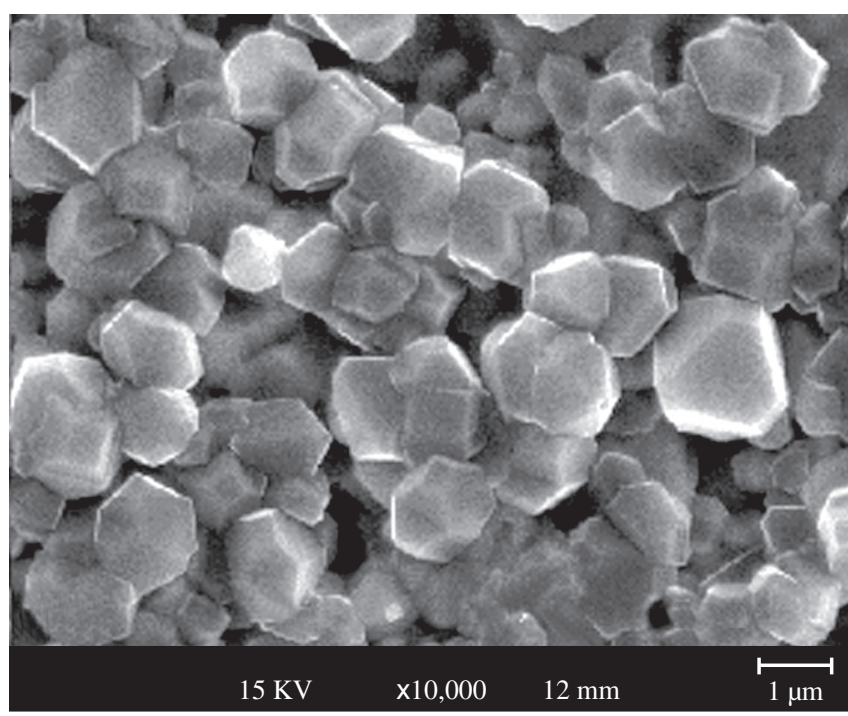

(e)

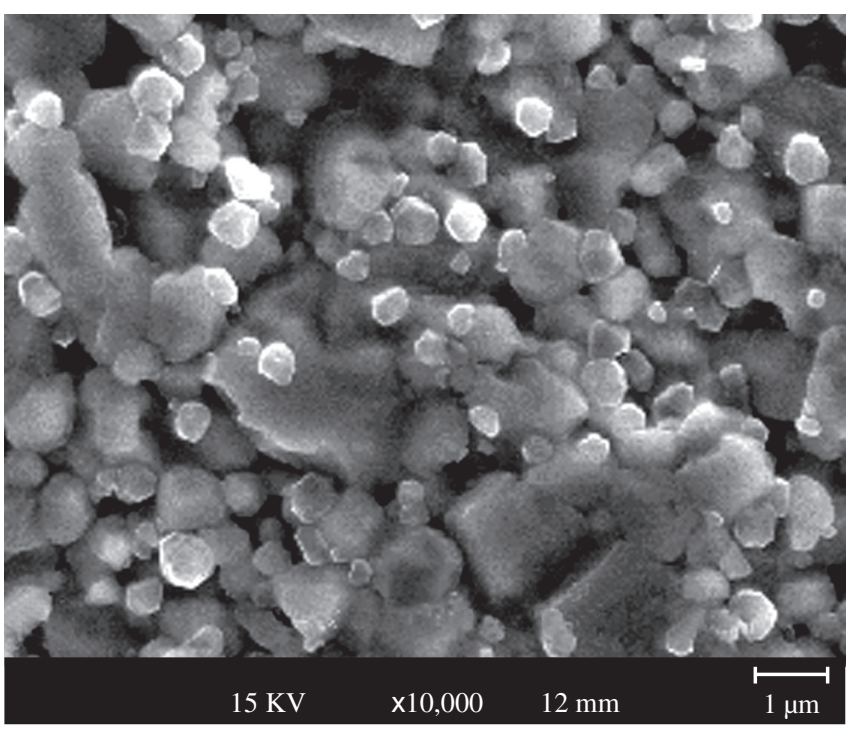

(b)

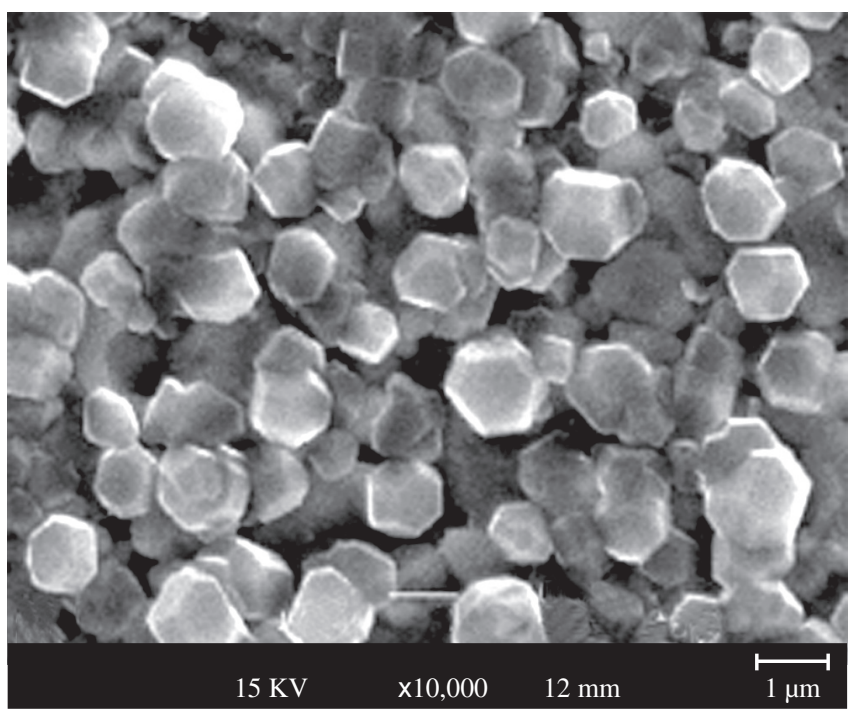

(d)

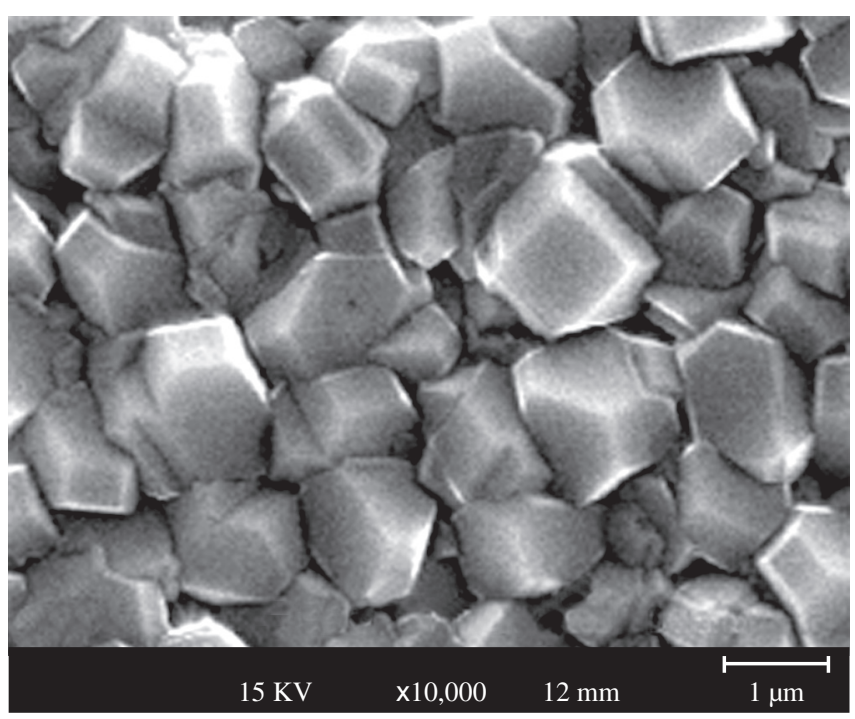

(f)

Figure 2. Micrographs of diamond crystal growth at various time a) 3 minutes, b) 3.5 minutes, c) 4 minutes, d) 5 minutes, e) 6 minutes and f) 10 minutes. 


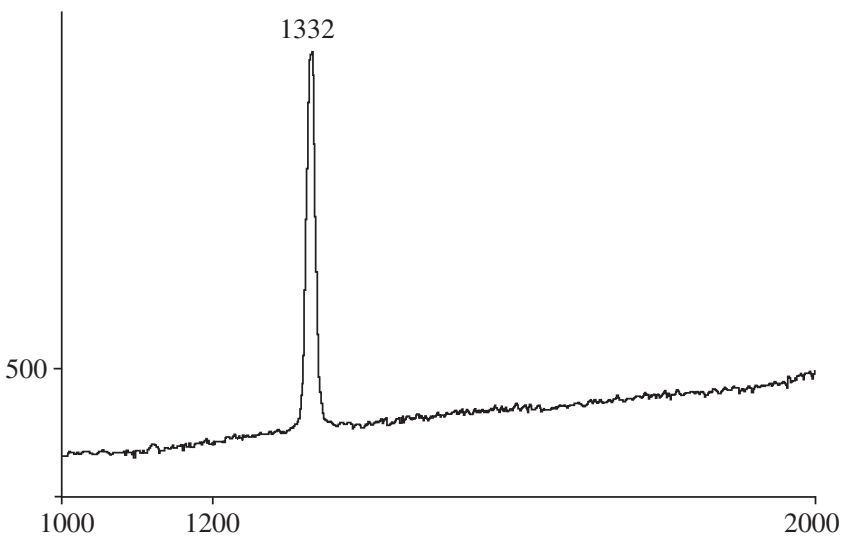

Figure 3. Raman Spectrum of the diamond film.

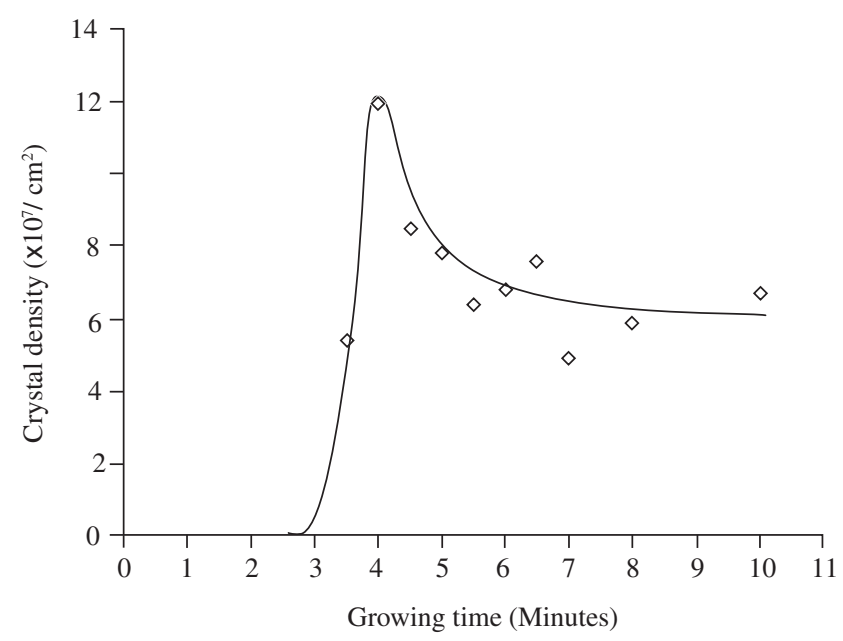

Figure 4. Crystal density versus growing time.

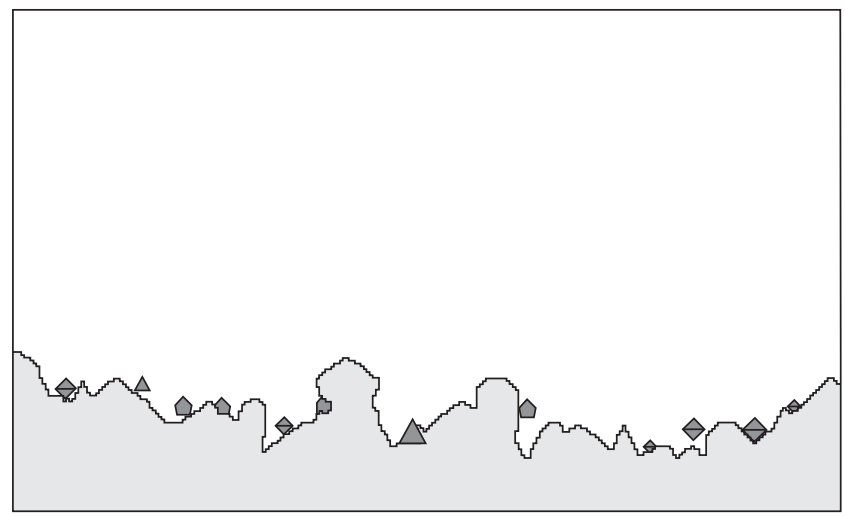

(a) is more probably caused by the stress in reinforced directions on thin stems in the porous layer by the thermal expansion/contraction from rough substrate surface. The stress in the diamond film detected by Raman spectroscopy ${ }^{24}$ is more likely to be the result of the competitive growth and the thermal expansion mismatch among crystals with different orientation, rather than the thermal expansion mismatch of diamond film and substrate. The thickness and porosity of this porous layer is the function of nucleation density, substrate surface roughness, nucleation uniformity in position and time, crystal orientation and growth rate. The rougher the substrate surface, the greater the possibility for the thicker porous layer. The porous interface layer is considered the weakest part; smooth substrate reduced the porous interface layer to the minimum thickness.

To develop a dense interface with high contacting area, high uniformity of nucleation and smooth substrate surface is required. The requirement for high uniformity of nucleation and smooth substrate surface is in contradiction with the idea of increasing adhesion through

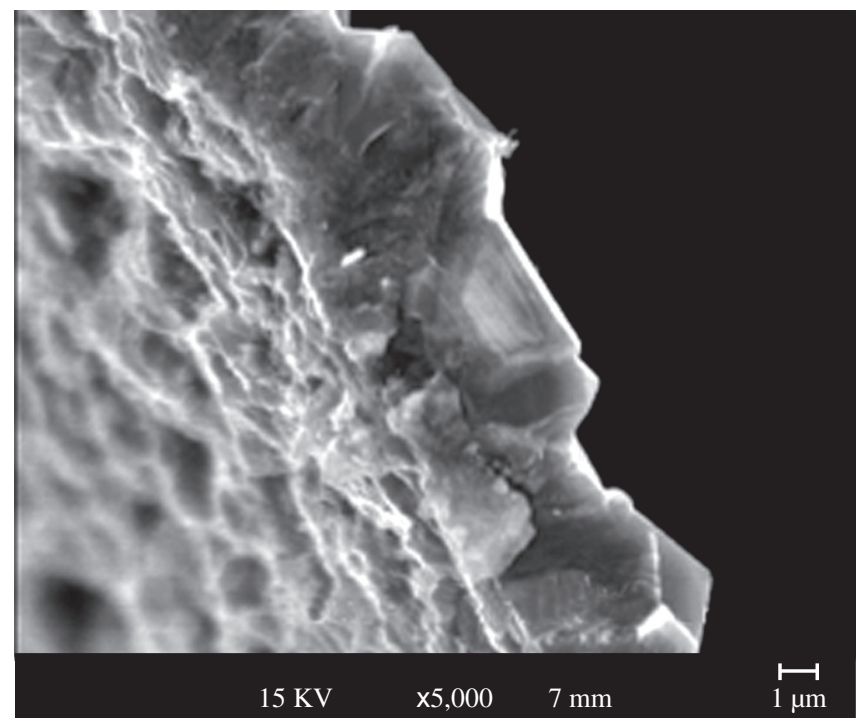

Figure 5. Cross-sectional view of diamond film.

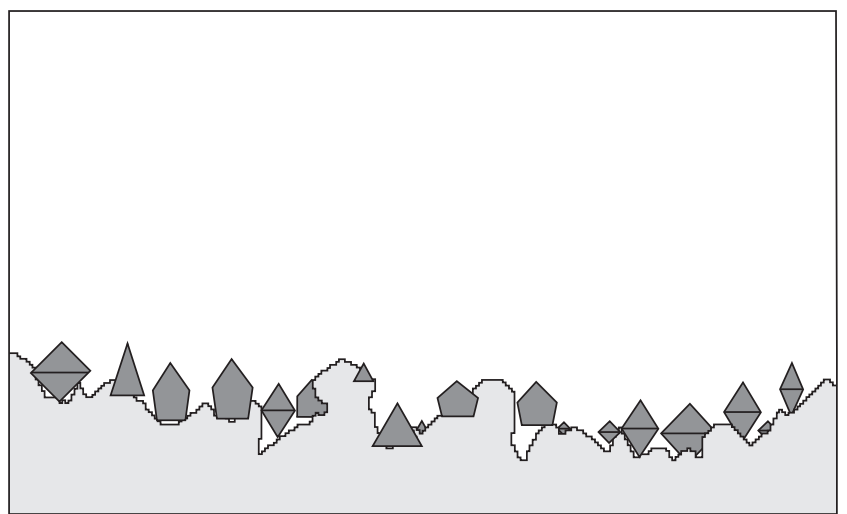

(b)

Figure 6. Model of the formation of the diamond film from a) to h). 


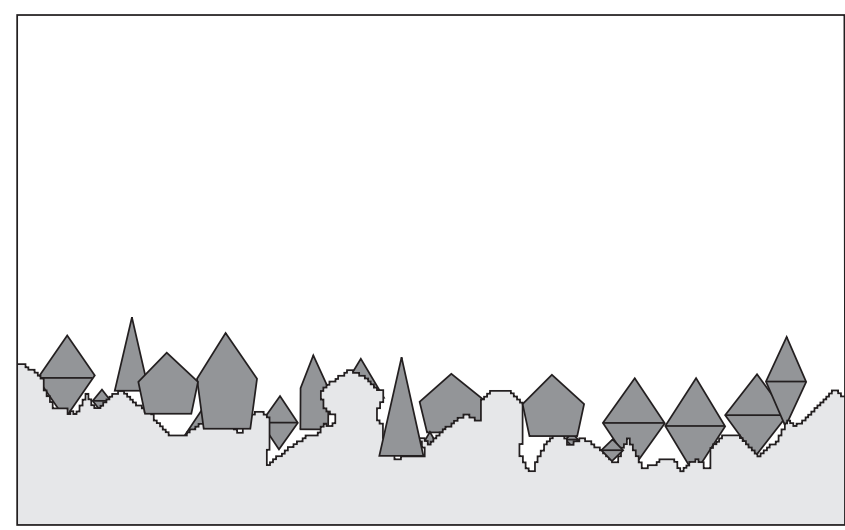

(c)

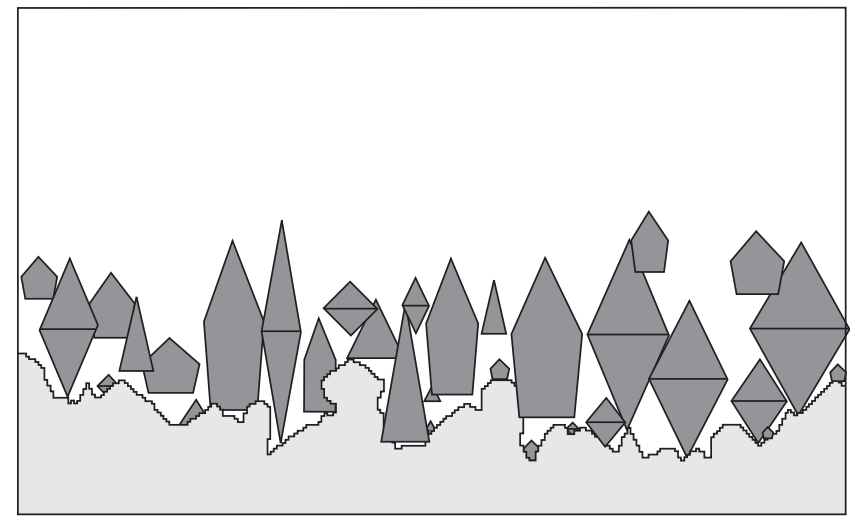

(e)

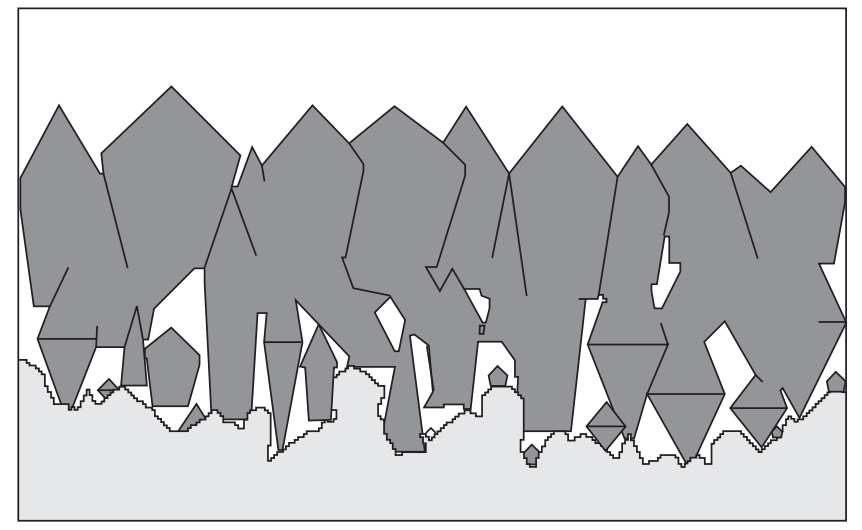

(g)

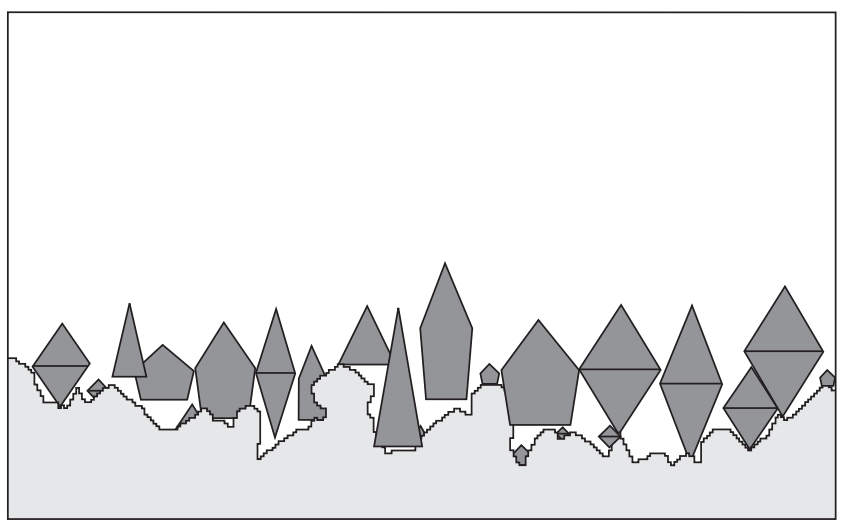

(d)

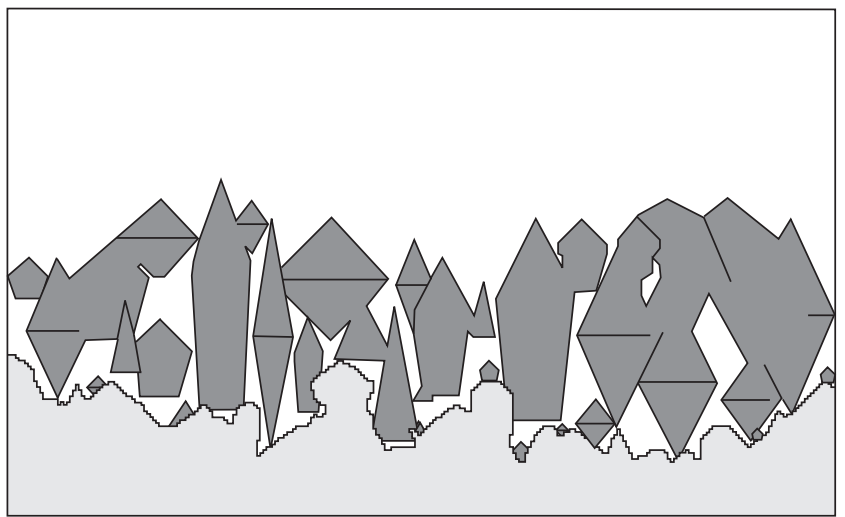

(f)

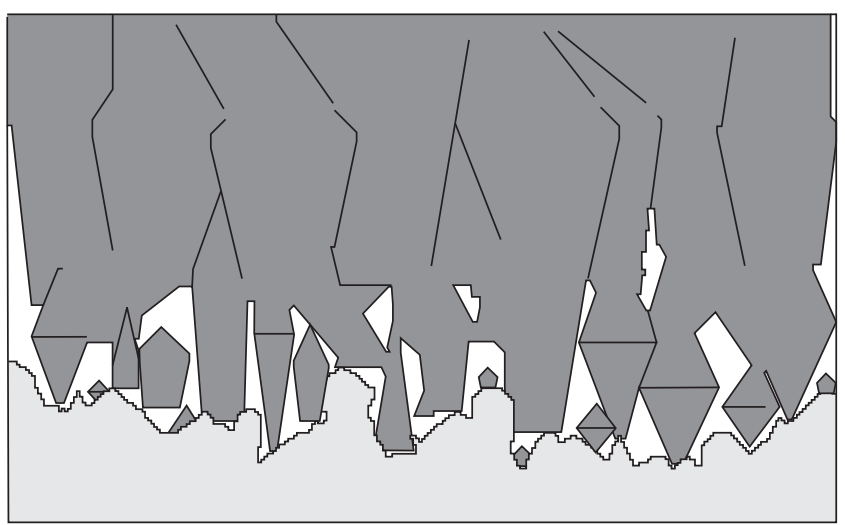

(h)

Figure 6 (Continued). Model of the formation of the diamond film from a) to $h$ ).

physical interlocking mechanism by increasing the roughness of the substrate surface. It is the porous interface layer that is not considered in physical interlocking mechanism.

\section{Summary}

High purity diamond film has been grown by refined Combustion Flame method with high oxygen proportion. Snapshots of time series of the diamond film forming were taken and a model was derived. From the model, it is clear that the interface of the film was porous. The porosity and thickness of this porous interface depend upon the nucleation density and growth rate. For the continuous diamond film with crystalline size of a few micron, the contacting area between the film and the substrate was found to be only $5-14 \%$ of the total substrate surface area. This value helps us to understand numerically how poor the adhesion was. To enhance adhesion of the film, the contacting area between the film and the substrate must be increased, and the porous interface layer must be thin and dense as much as possible. To achieve that, very high and uniform nucleation is the key. Under this view, the nanocrystalline diamond film on smooth substrate is preferred to have stronger adhesion

\section{Acknowledgements}

This work was funded by the National Metal and Materials Technology Center, Thailand (MTEC) and supported by King Mongkut's 
University of Technology Thonburi, Thailand (KMUTT). The authors would like to thank Prof. Narongrit Sombatsompop at KMUTT for his support and facilitating the experiments in this study.

\section{References}

1. Paul WM. CVD Diamond - a New Technology for the Future? Endeavour Magazine. 1995; 19(3): 101-106.

2. Sahoo B, Chattopadhyay AK. On effectiveness of various surface treatments on adhesion of HF-CVD diamond coating to tungsten carbide inserts. Diamond and Related Materials 2002; 11(9): 1660-1669.

3. Buck V, Deuerler F. Enhanced nucleation of diamond films on pretreated substrates. Diamond and Related Materials 1998; 7(10): 1544-1552.

4. Zhang ZM, He XC, Shen HS, Sun FH, Chen M, Wan YZ. Pre-treatment for diamond coatings on free-shape WC-Co tools. Diamond and Related Materials 2000; 9(9-10): 1749-1752.

5. Silva S, Mammana V, Salvadori MC, Monteiro OR, Brown IG. WC--Co cutting tool inserts with diamond coatings. Diamond and Related Materials 1999; 8(10): 1913-1918.

6. Chen M, Jian XG, Sun FH, Hu B, Liu XS. Development of diamondcoated drills and their cutting performance. Journal of Materials Processing Technology 2002; 129(1-3): 81-85.

7. Marinkovic S, Stankovic S, Rakocevic Z. Effects of cemented carbide surface pretreatment in combustion flame chemical vapour deposition of diamond. Thin Soid Films 1999; 354(1-2): 118-128.

8. ASTM E 407-93. Standard Practice for Microetching Metals and Alloys. USA: ASTM International; 1997.

9. Schermer JJ, Elst WALM, Giling LJ. The influence of differences in gas phase between turbulent and laminar acetylene-oxygen combustion flames on diamond growth. Diamond and Related Materials 1995; 4(9): 1113-1125.

10. Hiraki A. Low-temperature $\left(200^{\circ} \mathrm{C}\right)$ growth of diamond on nano-seeded substrates. Applied Surface Science 2000; 162-163: 326-331.

11. Lux B, Haubner R. Nucleation and Growth of Low-Pressure Diamond. NATO ASI Series B, Physics 1991; 266: 579-609.

12. Murakawa M, Takeuchi S. Fabrication of Diamond-Coated Cutting Insert Using an Improved Atmospheric Chamber Flame Method. Diamond Films Technology 1993; 2(4): 183-199.
13. Yan B, Loh NL, Fu Y, Sun CQ. Surface and interface characterization of diamond coatings deposited on pure titanium. Surface and Coatings Technology 1999; 115(2-3): 256-265.

14. Lee ST, Lam YW. Pressure effect on diamond nucleation in a hot-filament CVD system. Physical Review B 1997; 55(23): 15937-15941.

15. Stubhan F, Ferguson M, Füsser, H J. Heteroepitaxial nucleation of diamond on $\mathrm{Si}(001)$ in hot filament chemical vapor deposition. Applied Physics Letters 1995; 66(15): 1900-1902.

16. Stoner BR, Ma GHM, Wolter SD, Glass JT. Characterization of Biasenhanced Nucleation of Diamond on Silicon by In Vacuo Surface Analysis and Transmission Electron Microscopy. Physical Review B 1992; 45(19): 11067-11084.

17. Yugo S, Kanai T, Kimura T, Muto T. Generation of diamond nuclei by electric field in plasma chemical vapor deposition. Applied Physics Letters 1991; 58(10): 1036-1038.

18. Chen Q, Lin Z. Electron-emission-enhanced diamond nucleation on $\mathrm{Si}$ by hot filament chemical vapor deposition. Applied Physics Letters 1996; 68(17): 2450-2452.

19. Chen Q, Yang J, Lin Z. Synthesis of oriented textured diamond films on silicon via hot filament chemical vapor deposition. Applied Physics Letters 1995; 67(13): 1853-1855.

20. Wang WL, Liao KJ, Zhang RQ. Plasma associated diamond nucleation on AlN in hot-filament chemical vapor deposition. Materials Letters 2000; 44(6): 336-340.

21. Makita H, Nishimura K, Jiang N, Hatta A, Ito T, Hiraki A. Ultrahigh particle density seeding with nanocrystal diamond particles. Thin Solid Films. 1996; 281-282(1-2): 279-281.

22. Feng Z, Komvopoulos K, Bogy DB, Ager III JW, Anders S, Anders A, Wang Z, Brown IG. Effect of pretreatment process parameters on diamond nucleation on unscratched silicon substrates coated with amorphous carbon films. Journal of Applied Physics 1996; 79(1): 485-492.

23. Tang W, Wang Q, Wang S, Lu F. Adherent diamond coatings on cemented carbide substrates with different cobalt contents. Diamond and Related Materials 2001; 10(9-10): 1700-1704.

24. Park JK, Lee WS, Baik YJ. Grain size refinement of the diamond film deposited on the WC-Co cutting inserts using direct current biasing. Surface and Coatings Technology 2002; 171(1-3):1-5 